\title{
Calcitonin measurement in fine-needle aspirate washout fluid by electrochemiluminescence immunoassay for thyroid tumors
}

Minoru Kihara ${ }^{1 *}$ D, Mitsuyoshi Hirokawa ${ }^{2}$, Takumi Kudo ${ }^{3}$, Toshitetsu Hayashi ${ }^{2}$, Masatoshi Yamamoto', Hiroo Masuoka', Takuya Higashiyama', Mitsuhiro Fukushima', Yasuhiro Ito ${ }^{1}$, Akihiro Miya ${ }^{1}$ and Akira Miyauchi ${ }^{1}$

\begin{abstract}
Purpose: For the differential diagnosis of medullary thyroid carcinoma (MTC) on thyroid nodules, ultrasoundguided fine-needle aspiration cytology is a useful and safe procedure, but its diagnostic accuracy is not high enough. As an ancillary method to accurately diagnose MTC, the calcitonin in fine-needle aspirate washout fluid (FNA-Ct) is used. However, no data are available about cut-off values of FNA-Ct using the currently available electrochemiluminescence immunoassay (ECLIA).

Methods: We investigated 180 thyroid nodules in 141 patients. After smearing, the syringe and needle used for the FNA were rinsed with normal saline $(0.5 \mathrm{~mL})$. The calcitonin in the washout was measured by ECLIA.

Results: The FNA-Ct in the non-MTC nodules of MTC patients, non-MTC nodules of non-MTC patients, and MTC nodules were 10.6-2100 pg/mL (median $24.6 \mathrm{pg} / \mathrm{mL}$ ), $<0.5-21.0 \mathrm{pg} / \mathrm{mL}$ (median $<0.5 \mathrm{pg} / \mathrm{mL}$ ), and 94.9-4,070,000 pg/mL (median 177,000 pg/mL), respectively. A receiver operating characteristic analysis of the MTC nodules and the non-MTC nodules of the non-MTC patients indicated that the cut-off value was $21.0 \mathrm{pg} / \mathrm{mL}$, leading to $100 \%$ sensitivity and $100 \%$ specificity.
\end{abstract}

Conclusions: This is the first study to determine the cut-off value of FNA-Ct with an ECLIA, and we propose that the optimal cut-off value is $21.0 \mathrm{pg} / \mathrm{mL}$.

Keywords: Calcitonin, Fine-needle aspiration washout fluid, Medullary thyroid carcinoma,

Electrochemiluminescence immunoassay, ECLIA

\section{Introduction}

Medullary thyroid carcinoma (MTC) is a quite rare malignant tumor that originates from $\mathrm{C}$ cells (calcitonin-producing cells), which represent $<1 \%$ of the total cells within the thyroid gland. MTC presents in a sporadic or hereditary variant $[1,2]$. Serum calcitonin is the most sensitive biochemical marker for MTC for both the primary diagnosis and follow-up [3-9]. For the preoperative diagnosis of thyroid nodules, ultrasound-guided fine-needle aspiration cytology (FNAC) is a

\footnotetext{
* Correspondence: kihara@kuma-h.or.jp

${ }^{1}$ Departments of Surgery, Kuma Hospital, 8-2-35 Shimoyamate-dori, Chuo-ku, Kobe, Hyogo 650-0011, Japan

Full list of author information is available at the end of the article
}

useful and safe procedure, but the diagnostic accuracy of this method for MTC is not as high as it is for papillary thyroid carcinoma (PTC) [10-15]. In their 2015 meta-analysis of 15 studies, Trimboli et al. [16] stated that the accuracy of FNAC in diagnosing MTC in patients with MTC nodules was $<50 \%$. However, other studies have indicated that the measurement of calcitonin in the fine-needle aspirate washout fluid from thyroid nodules may significantly improve the sensitivity of the diagnosis of MTC [17-20].

Calcitonin has generally been determined using a solid-phase, two-site chemiluminescent immunometric assay or the solid two-site immunoradiometric assay that is available worldwide. In Japan, until March 2015, 
calcitonin was measured using the solid two-site immunoradiometric assay only. In April 2015, the measurement method in Japan was changed to an electrochemiluminescence immunoassay (ECLIA). To the best of our knowledge, no data are available about the appropriate cut-off value of calcitonin in fine-needle aspirate washout fluid (FNA-Ct) using this current calcitonin assay system in MTC patients and non-MTC patients. We conducted the present study to assess the feasibility of cut-off values of FNA-Ct obtained with the use of an ECLIA in both MTC and non-MTC patients.

\section{Patients and methods}

\section{Patients}

At our hospital, 103 patients had 142 thyroid nodules which were suspicious for MTC or could not be ruled out as MTC clinically and preoperatively in the period from April 2015 to November 2017. Another 38 patients had 38 thyroid nodules which were suspicious for tumors other than MTC on ultrasonography in November 2017. These 38 patients were enrolled as the control group in this study, which was approved by the Ethics Committee at our hospital. Written informed consent for their case to be used was obtained from each patient. Ultimately, a total of 141 patients were enrolled: 45 males and 96 females, median age 60 years (range $16-88$ years).

\section{Methods}

FNAC was performed by using a 22-gauge needle under ultrasound guidance. After smearing, the remaining aspirate in the syringe and needle used for the aspiration was rinsed with $0.5 \mathrm{~mL}$ of normal saline. The aspirate was then subjected to calcitonin measurements. The serum calcitonin was also measured in the patients suspected of having MTC. Calcitonin was measured by a laboratory (SRL Co., Tokyo) using the Elecsys ${ }^{\circ}$ Calcitonin test system (Roche Diagnostics, Tokyo), which is an ECLIA. According to the manufacturer, the normal ranges of serum calcitonin are $\leq 9.52 \mathrm{pg} / \mathrm{mL}$ for males and $\leq 6.40 \mathrm{pg} / \mathrm{mL}$ for females, with a lower detection limit of quantification of $0.5 \mathrm{pg} / \mathrm{mL}$.

All 141 patients underwent a thyroidectomy. The diagnosis of MTC necessarily involved histological and immunohistochemical examinations using antibodies against calcitonin and carcinoembryonic antigen (CEA). None of the patients had hyperparathyroidism, hepatic cirrhosis, or renal insufficiency. None of the patients had been treated with drugs that increase calcitonin secretion (such as omeprazole, beta-blockers and glucocorticoid secretagogues), and none were cigarette smokers. In all of the patients, the preoperative thyroid function was euthyroidism.

\section{Statistical analysis}

For the comparison of continuous variables, the Mann-Whitney U-test was used. A $p$-value $<0.05$ was regarded as significant. All analyses were performed using StatFlex 6.0 software (Artech, Osaka, Japan).

\section{Results}

FNAC, FNA-Ct, and surgery were performed in 180 nodules in the 141 patients, and 39 of these nodules were diagnosed as MTCs histopathologically. The other histopathological diagnoses included papillary carcinoma (14 nodules), poorly differentiated carcinoma (two nodules), anaplastic carcinoma (one nodule), nodular goiter (93 nodules), follicular neoplasm (17 nodules), chronic thyroiditis (eight nodules), cyst (five nodules), and intrathyroid thymic carcinoma (one nodule).

The serum calcitonin values of the non-MTC patients were within the normal limits (maximum $6.7 \mathrm{pg} / \mathrm{mL}$ ), whereas those of the MTC patients ranged from $86.0 \mathrm{pg} / \mathrm{mL}$ to $4970 \mathrm{pg} / \mathrm{mL}$ (median $379 \mathrm{pg} / \mathrm{mL}$ ).

The FNA-Ct values in the non-MTC nodules of the MTC patients ranged from $10.6 \mathrm{pg} / \mathrm{mL}$ to $2100 \mathrm{pg} / \mathrm{mL}$ (median $24.6 \mathrm{pg} / \mathrm{mL}$ ), and those values in the non-MTC nodules of the non-MTC patients ranged from $<0.5 \mathrm{pg} /$ $\mathrm{mL}$ to $21.0 \mathrm{pg} / \mathrm{mL}$ (median $<0.5 \mathrm{pg} / \mathrm{mL}$ ) (Fig. 1). These values were significantly higher in the non-MTC nodules of the MTC patients than in the non-MTC nodules of the non-MTC patients $(p<0.0001)$ (Fig. 1).

The FNA-Ct values in the MTC nodules ranged $94.9 \mathrm{pg} / \mathrm{mL}$ to $4,070,000 \mathrm{pg} / \mathrm{mL}$ (median $177,000 \mathrm{pg} / \mathrm{mL}$ ) (Fig. 2), which is significantly higher than in the non-MTC nodules of non-MTC patients $(p<0.0001)$ (Fig. 2).

In a receiver operating characteristic (ROC) analysis for the MTC nodules and the non-MTC nodules of the non-MTC patients, the area under the curve (AUC) was $100 \%$ : on the basis of this curve, the cut-off value of FNA-Ct was $21.0 \mathrm{pg} / \mathrm{mL}$, leading to $100 \%$ sensitivity and $100 \%$ specificity (Fig. 3 ).

The FNA-Ct/serum calcitonin ratios in the MTC nodules of the MTC patients ranged from 0.48 to $2583 \mathrm{pg} / \mathrm{mL}$ (median $212.0 \mathrm{pg} / \mathrm{mL}$ ), and those ratios in the non-MTC nodules of the MTC patients ranged from 0.009 to $39.0 \mathrm{pg} / \mathrm{mL}$ (median 0.25) (Fig. 4). These ratios were significantly higher in the MTC nodules of the MTC patients than in the non-MTC nodules of the MTC patients $(p<0.0001)$ (Fig. 4). In a ROC analysis for the MTC nodules and the non-MTC nodules of the MTC patients, the AUC was 97.1\%: on the basis of this curve, the cut-off value of FNA-Ct/serum calcitonin ratio was 11.0 , leading to $100 \%$ sensitivity and $86.7 \%$ specificity (Fig. 5).

The Table 1 provides the data of the non-MTC nodules of the MTC patients. The FNA-Ct value and FNA-Ct/serum calcitonin ratio were higher in the 


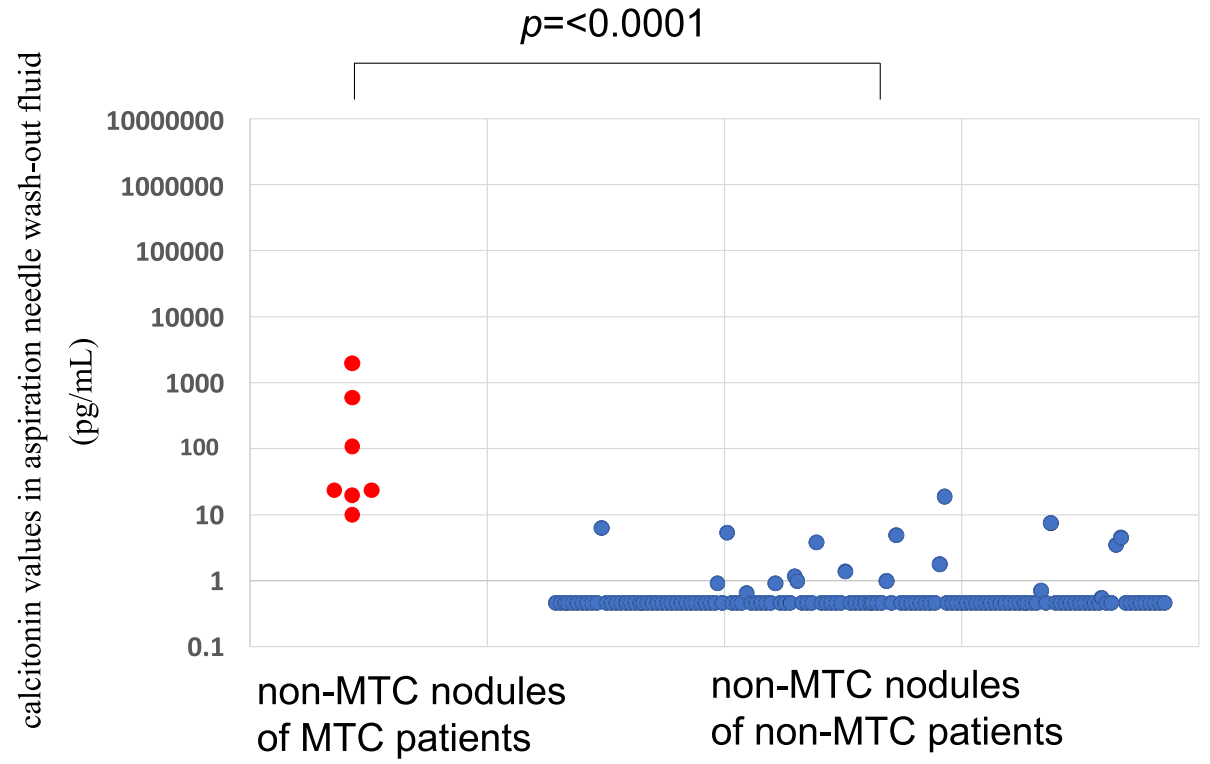

Fig. 1 Calcitonin values in fine-needle aspirate washout fluid using ECLIA in non-MTC nodules

hereditary MTC patients compared to the sporadic MTC patients.

\section{Discussion}

FNAC is a safe, accurate, and cost-effective method for the initial screening of thyroid nodules [21], but the diagnostic accuracy of this method for MTC is not as high as it is for PTC [10-15]. The diagnostic accuracy provided by FNAC for MTCs ranges from 50.0 to $82.4 \%$ $[10,12,15,16,22]$, because cytologic examination results have revealed diverse appearances include a variety of cellular morphologies, non-typical cell shapes, and low cellularity in MTC $[10,11]$. Serum calcitonin is the most sensitive tumor marker for MTC, and its measurement is used to follow patients with residual and metastatic MTC [23-25]. Elisei et al. [26] reported that serum calcitonin had higher sensitivity compared to cytology. However, high levels of serum calcitonin do not reveal which of multiple lesions is MTC.

A preoperative diagnosis of MTC is very important to the determination of the need for genetic testing for a germline RET mutation analysis and the surgical

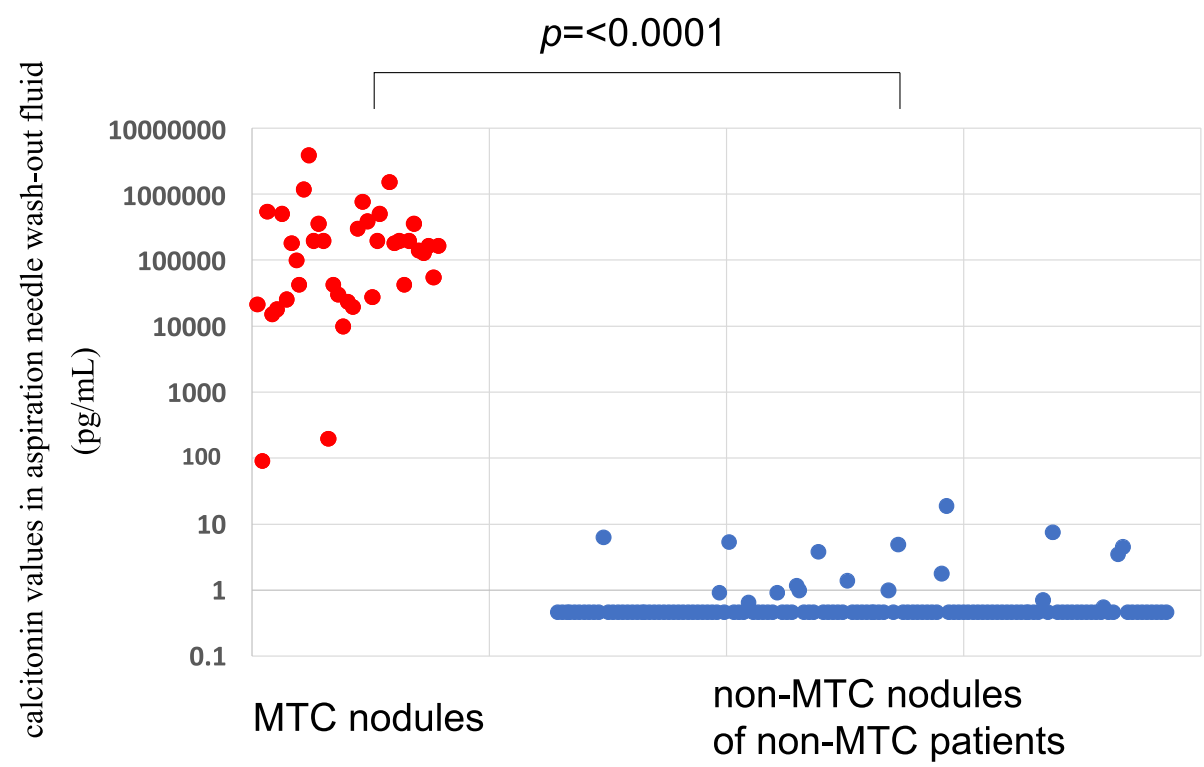

Fig. 2 Calcitonin values in fine-needle aspirate washout fluid using ECLIA in the MTC nodules and in the non-MTC nodules of non-MTC patients 


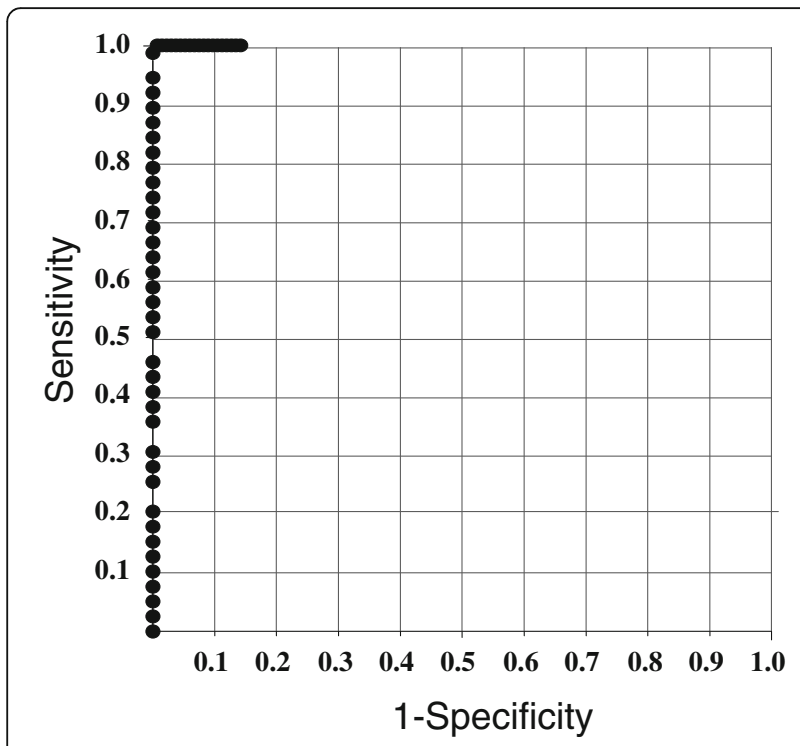

Fig. 3 ROC curve of Calcitonin values in fine-needle aspirate washout fluid using ECLIA in the MTC nodules and in the non-MTC nodules of non-MTC patients

procedure. Several reports including our previous paper demonstrated that calcitonin measurements in aspiration needle wash-out fluid have increased the accuracy of diagnosis as an ancillary method [17-20]. The first papers were published by Boi et al. [17] and Kudo et al. [18] in 2007. According to the most updated American Thyroid Association (ATA) guidelines, FNA-Ct should be used to accurately diagnose MTC and avoid false-negative or inconclusive/nondiagnostic results from cytology [1]. In their review, Trimboli et al. [20] stated that different calcitonin cut-off levels $(7.4-67 \mathrm{pg} / \mathrm{mL})$ had been obtained by different criteria calculation and different assay methods. The methods used to measure calcitonin have changed worldwide over the years, from the solid two-site immunoradiometric assay (RIA) to the use of a solid-phase, enzyme-labeled, two-site chemiluminescent immunometric assay with increasing sensitivity [27]. We reported that the cut-off level to be used with an RIA was $67.0 \mathrm{pg} / \mathrm{mL}$ [18].

As noted in the Introduction, calcitonin measurement in Japan has been conducted using only ECLIAs since April 2015. We have found no data regarding the cut-off values of FNA-Ct to be used with the currently available calcitonin assay system, and we used this assay in the present study. This study is the first report of the cut-off value to be used with ECLIAs. Our ROC curve analysis for MTC nodules and non-MTC nodules of non-MTC patients revealed that the optimal cut-off value was $21.0 \mathrm{pg} / \mathrm{mL}$, leading to $100 \%$ sensitivity and $100 \%$ specificity. On the other hand, Our ROC curve analysis for MTC nodules and non-MTC nodules of MTC patients revealed that the cut-off value of FNA-Ct/serum calcitonin ratio was 11.0 , leading to $100 \%$ sensitivity and $86.7 \%$ specificity.

It is remarkable that the FNA-Ct values of all MTC nodules were high $(>94.9 \mathrm{pg} / \mathrm{mL})$ and those of almost all of the non-MTC nodules were $<0.5 \mathrm{pg} / \mathrm{mL}$, whereas the values of some non-MTC nodules from MTC

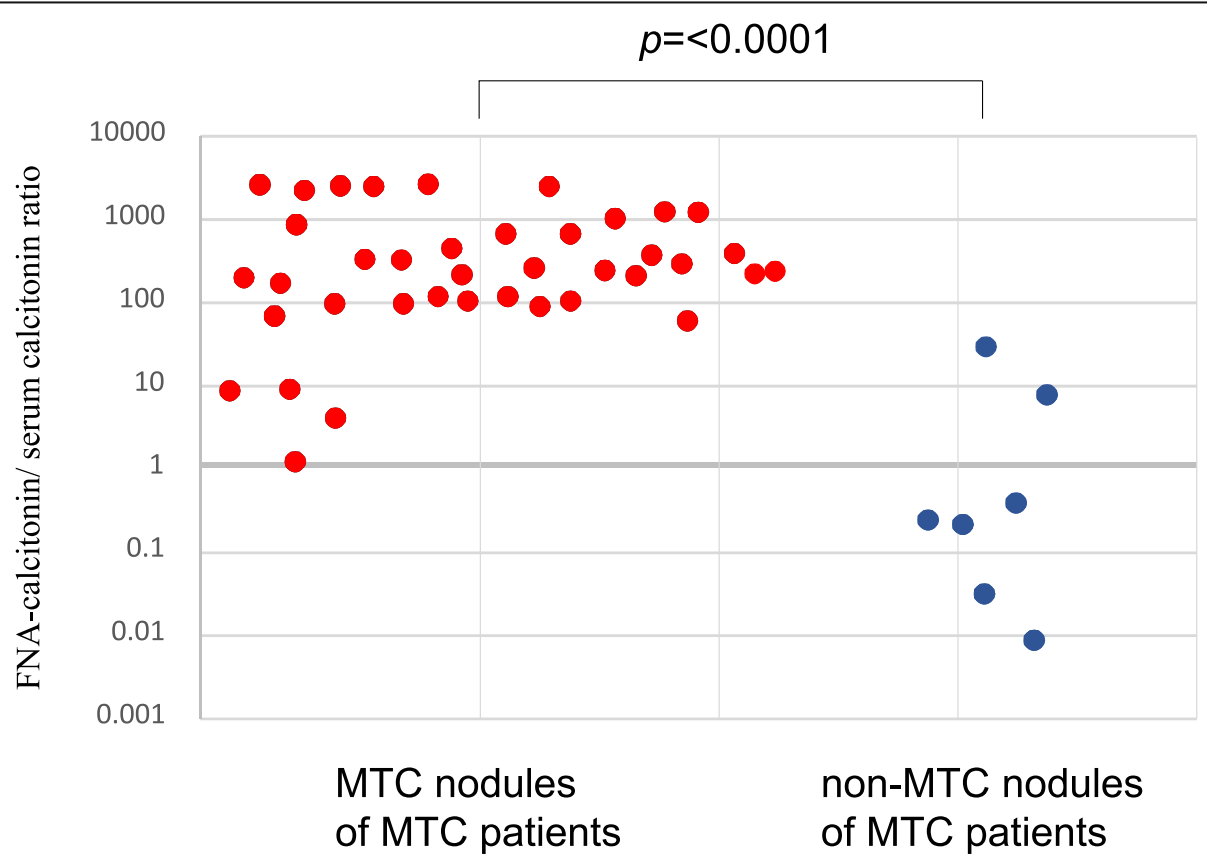

Fig. 4 The FNA-Ct / serum calcitonin ratios in the MTC nodules and the non-MTC nodules of the MTC patients 


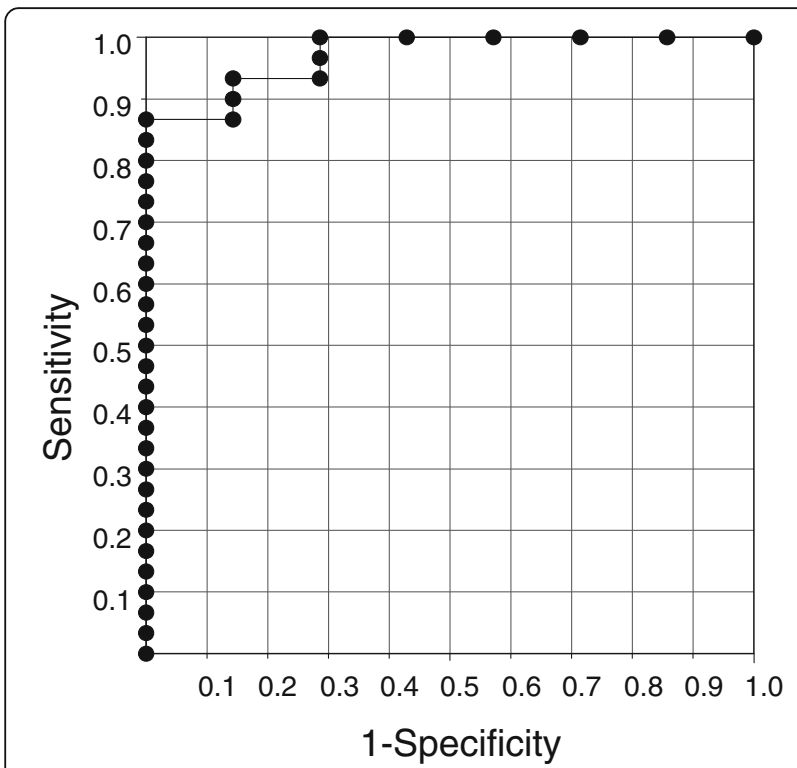

Fig. 5 ROC analysis for the MTC nodules and the non-MTC nodules of the MTC patients

patients were high. The FNA-Ct is directly influenced by serum calcitonin due to peripheral blood contamination [17]. The FNA-Ct values of six of the seven non-MTC nodules in MTC patients (all serum calcitonin levels were higher than the normal range) were high $(>21.0 \mathrm{pg} / \mathrm{mL})$ in the present study. In addition, the FNA-Ct value and FNA-Ct/serum calcitonin ratio were higher in the hereditary MTC patients compared to the sporadic MTC patients. For this reason, we speculate that in the hereditary MTC patients, perhaps the $\mathrm{C}$-cell hyperplasia in the areas surrounding non-MTC nodules was also punctured by the aspiration when FNAC was performed. Thus, in MTC patients the levels of serum calcitonin are high and the nodules for which the values of FNA-Ct are lower can be classified as negative, indicating the need for careful judgment regarding nodules with

Table 1 Comparison of the non-MTC nodules in hereditary MTC patients and in sporadic MTC patients

\begin{tabular}{lllll}
\hline Patient & $\begin{array}{l}\text { FNA-Ct } \\
(\mathrm{pg} / \mathrm{mL})\end{array}$ & $\begin{array}{l}\text { Serum calcitonin } \\
(\mathrm{pg} / \mathrm{mL})\end{array}$ & $\begin{array}{l}\text { FNA-Ct /Serum } \\
\text { calcitonin ratio }\end{array}$ & $\begin{array}{l}\text { Sporadic or } \\
\text { Hereditary } \\
\text { MTC patients }\end{array}$ \\
\hline 1 & 10.6 & 26.8 & 0.40 & sporadic \\
2 & 21.2 & 640 & 0.03 & sporadic \\
3 & 24.4 & 112 & 0.22 & sporadic \\
4 & 24.6 & 2600 & 0.01 & sporadic \\
5 & 112 & 458 & 0.25 & sporadic \\
6 & 623 & 15.9 & 39.2 & hereditary \\
7 & 2100 & 282 & 7.45 & hereditary \\
\hline
\end{tabular}

high FNA-Ct values, especially in hereditary MTC patients. In such cases, it may be effective to conduct an immunocytochemical analysis for calcitonin to identify MTC. However, the feasibility of this procedure is limited to cytologic samples with adequate cellularity, and MTCs may be not identified on inadequate or suboptimal cytologic specimens [20].

\section{Conclusions}

In conclusion, this study is the first to identify the calcitonin cut-off value in fine-needle aspirate washout fluid for use with the currently available calcitonin assay system and an ECLIA. We propose that the calcitonin cut-off value in fine-needle aspirate washout fluid using a calcitonin assay system with an ECLIA is $21.0 \mathrm{pg} / \mathrm{mL}$.

\section{Abbreviations}

ATA: American Thyroid Association; AUC: Area under the curve; CEA: Carcinoembryonic antigen; ECLIA: Electrochemiluminescence immunoassay; FNAC: Fine-needle aspiration cytology; FNA-Ct: fine-needle aspirate washout fluid; MTC: Medullary thyroid carcinoma; PTC: Papillary thyroid carcinoma; RIA: Immunoradiometric assay; ROC: Receiver operating characteristic

\section{Acknowledgements}

Not applicable.

\section{Funding}

Not applicable.

\section{Availability of data and materials}

All data is contained within the manuscript and additional files.

\section{Authors' contributions}

MK was involved in the study design, collection, analysis, interpretation of data and writing of the manuscript. MH was involved in date collection and histopathological examination. AM was involved in the study design. TK was involved in data analysis. TH was involved in histopathological examination. MY, HM, TH, MF, YI and AM were involved in data analysis. All authors read and approved the final manuscript.

\section{Ethics approval and consent to participate}

This study was approved by the Ethics Committee in Kuma Hospital. Written informed consent for their case to be used was obtained from each patient.

\section{Consent for publication}

All authors provide consent for this publication.

\section{Competing interests}

The authors declare that they have no competing interests.

\section{Publisher's Note}

Springer Nature remains neutral with regard to jurisdictional claims in published maps and institutional affiliations.

\section{Author details}

'Departments of Surgery, Kuma Hospital, 8-2-35 Shimoyamate-dori, Chuo-ku, Kobe, Hyogo 650-0011, Japan. ${ }^{2}$ Departments of Diagnostic Pathology, Kuma Hospital, 8-2-35 Shimoyamate-dori, Chuo-ku, Kobe, Hyogo 650-0011, Japan. ${ }^{3}$ Departments of Internal Medicine, Kuma Hospital, 8-2-35 Shimoyamate-dori, Chuo-ku, Kobe, Hyogo 650-0011, Japan. 
Received: 17 August 2018 Accepted: 17 October 2018

Published online: 30 October 2018

\section{References}

1. Wells SA Jr, Asa SL, Dralle H, Elisei R, Evans DB, Gagel RF, et al. Revised American Thyroid Association guidelines for the management of medullary thyroid carcinoma. Thyroid. 2015:25:567-610.

2. Elisei R, Alevizaki M, Conte-Devolx B, Frank-Raue K, Leite V, Williams GR. 2012 European Thyroid Association guidelines for genetic testing and its clinical consequences in medullary thyroid cancer. Eur Thyroid J. 2013;1:216-31.

3. Bugalho MJM, Santos JR, Sobrinho L. Preoperative diagnosis of medullary thyroid carcinoma: fine needle aspiration cytology as compared with serum calcitonin measurement. J Surg Oncol. 2005:91:56-60.

4. Rodding AH, Levine SN, Fowler MR. Normal preoperative calcitonin levels do not always exclude medullary thyroid carcinoma in patients with large palpable thyroid masses. Thyroid. 2000;10:919-22.

5. Hamy A, Pessaux P, Mirallie E, Mucci-Hennekinne S, Gibelin H, Mor-Martinez $C$, et al. Central neck dissection in the management of sporadic medullary thyroid microcarcinoma. Eur J Sur Oncol. 2005;31:774-7.

6. Kudo T, Miyauchi A, Ito Y, Yabuta T, Inoue H, Higashiyama T, et al. Serum calcitonin levels with calcium loading tests before and after total thyroidectomy in patients with thyroid diseases other than medullary thyroid carcinoma. Endocr J. 2011;58:217-21.

7. Mian C, Perrino M, Colombo C, Cavedon E, Pennelli G, Ferrero S, et al. Refining calcium test for the diagnosis of medullary thyroid cancer: cutoffs, procedures, and safety. J Clin Endocrinol Metab. 2014:99:1656-64.

8. Kihara M, Miyauchi A, Kudo T, Hirokawa M, Miya A. Reference values of serum calcitonin with calcium stimulation tests by electrochemiluminescence immunoassay before/after total thyroidectomy in Japanese patients with thyroid diseases other than medullary thyroid carcinoma. Endocr J. 2016;63:627-32.

9. Kihara M, Miyauchi A, Kudo T, Hirokawa M, Miya A. Serum calcitonin reference values for calcium stimulation tests by electrochemiluminescence immunoassay in Japanese men with non-medullary thyroid carcinoma. Surg Today. 2018:48:223-8.

10. Chang TC, Wu SL, Hsiao YL. Medullary thyroid carcinoma: pitfalls in diagnosis by fine needle aspiration cytology and relationship of cytomorphology to RET proto-oncogene mutations. Acta Cytol. 2005;49:477-82.

11. Kaushal S, lyer VK, Mathur SR, Ray R. Fine needle aspiration cytology of medullary carcinoma of the thyroid with a focus on rare variants: a review of 78 cases. Cytopathology. 2011;22:95-105.

12. Trimboli $\mathrm{P}$, Cremonini N, Ceriani L, Saggiorato E, Guidobaldi L, Romanelli F, et al. Calcitonin measurement in aspiration needle washout fluids has higher sensitivity than cytology in detecting medullary thyroid cancer: a retrospective multicenter study. Clin Endocrinol. 2014:80:135-40.

13. de Crea C, Raffaelli M, Maccora D, Carrozza C, Canu G, Fadda G, et al. Calcitonin measurement in fine-needle aspirate washouts vs. cytologic examination for diagnosis of primary or metastatic medullary thyroid carcinoma. Acta Otorhinolaryngol Ital. 2014;34:399-405.

14. Haymart MR, Greenblatt DY, Elson DF, Chen $\mathrm{H}$. The role of intraoperative frozen section if suspicious for papillary thyroid cancer. Thyroid. 2008;18:419-23.

15. Suzuki A, Hirokawa M, Takada N, Higuchi M, Ito A, Yamao N, et al. Fineneedle aspiration cytology for medullary thyroid carcinoma: a single institutional experience in Japan. Endocr J. 2017:64:1099-104.

16. Trimboli P, Treglia G, Guidobaldi L, Romanelli F, Nigri G, Valabrega S, et al. Detection rate of FNA cytology in medullary thyroid carcinoma: a metaanalysis. Clin Endocrinol. 2015;82:280-5

17. Boi F, Maurelli I, Pinna G, Atzeni F, Piga M, Lai ML, et al. Calcitonin measurement in wash-out fluid from fine needle aspiration of neck masses in patients with primary and metastatic medullary thyroid carcinoma. J Clin Endocrinol Metab. 2007:92:2115-8.

18. Kudo T, Miyauchi A, Ito Y, Takamura Y, Amino N, Hirokawa M. Diagnosis of medullary thyroid carcinoma by calcitonin measurement in fine-needle aspiration biopsy specimens. Thyroid. 2007;17:635-8.

19. Diazzi C, Madeo B, Taliani E, Zirilli L, Romano S, Granata AR, et al. The diagnostic value of calcitonin measurement in wash-out fluid from fineneedle aspiration of thyroid nodules in the diagnosis of medullary thyroid cancer. Endocr Pract. 2013;19:769-79.
20. Trimboli P, Guidobaldi L, Bongiovanni M, Crescenzi A, Alevizaki M Giovanella $\mathrm{L}$. Use of fine-needle aspirate calcitonin to detect medullary thyroid carcinoma: a systematic review. Diagn Cytopathol. 2016;44:45-51.

21. Cooper DS, Doherty GM, Haugen BR, Kloos RT, Lee SL, Mandel SJ, et al. Revised American Thyroid Association management guidelines for patients with thyroid nodules and differentiated thyroid cancer. Thyroid. 2009:19:1167-214

22. K P, Nagel H, Droese M. Cytologic diagnosis of medullary carcinoma of the thyroid gland. Diagn Cytopathol. 2000;22:351-8

23. Ito $Y$, Miyauchi A, Yabuta T, Fukushima M, Inoue $H$, Tomoda C, et al. Alternative surgical strategies and favorable outcomes in patients with medullary thyroid carcinoma in Japan: experience of a single institution. World J Surg. 2009:33:58-66.

24. de Groot JW, Plukker JT, Wolffenbuttel BH, Wiggers T, Sluiter WJ, Links TP. Determinants of life expectancy in medullary thyroid cancer: age does not matter. Clin Endocrinol. 2006;65:729-36.

25. Pellegriti G, Leboulleux S, Baudin E, Bellon N, Scollo C, Travagli JP, et al. Long-term outcome of medullary thyroid carcinoma in patients with normal postoperative medical imaging. Br J Cancer. 2003:88:1537-42.

26. Elisei R, Bottici V, Luchetti F, Di Coscio G, Romei C, Grasso L, et al. Impact of routine measurement of serum calcitonin on the diagnosis and outcome of medullary thyroid cancer: experience in 10,864 patients with nodular thyroid disorders. J Clin Endocrinol Metab. 2004;89:163-8.

27. Rowland KJ, Jin LX, Moley JF. Biochemical cure after reoperations for medullary thyroid carcinoma: a meta-analysis. Ann Surg Oncol. 2015;22:96-102.
Ready to submit your research? Choose BMC and benefit from:

- fast, convenient online submission

- thorough peer review by experienced researchers in your field

- rapid publication on acceptance

- support for research data, including large and complex data types

- gold Open Access which fosters wider collaboration and increased citations

- maximum visibility for your research: over $100 \mathrm{M}$ website views per year

At BMC, research is always in progress.

Learn more biomedcentral.com/submissions 